\title{
Assessing the Bonding Interface Characteristics and Mechanical Properties of Bobbin Tool Friction Stir Welded Dissimilar Aluminum Alloy Joints
}

\author{
Quan Wen ${ }^{1,2} \cdot$ Wenya $\mathrm{Li}^{1} \cdot$ Vivek Patel $^{1} \cdot$ Luciano Bergmann $^{2} \cdot$ Benjamin Klusemann $^{2,3} \cdot$ Jorge F. dos Santos $^{2}$
}

Received: 17 March 2020 / Revised: 20 April 2020 / Accepted: 21 April 2020 / Published online: 8 July 2020

(c) The Chinese Society for Metals (CSM) and Springer-Verlag GmbH Germany, part of Springer Nature 2020

\begin{abstract}
This study focuses on the bonding interface characteristics and mechanical properties of the bobbin tool friction stir welded dissimilar AA6056 and AA2219 aluminum alloy joints using different welding speeds. Voids arise solely in the stir zone at the AA2219 side. A distinct boundary with limited material mixing develops at the middle section of the bonding interface, while excellent material mixing with an irregularly jagged pattern forms at the top and bottom sections of the bonding interface. Increasing the welding speed, the material mixing is rarely changed at the middle section in comparison with the bottom section. Furthermore, a small difference between Guinier-Preston dissolution and $Q$ phase precipitation leads to rare change of hardness in the heat affected zone (HAZ) at the AA6056 side. The increased hardness of the HAZ at the AA2219 side is attributed to avoidance of the dissolution of $\theta^{\prime \prime}$ phase precipitates. A maximum tensile strength of $181 \mathrm{MPa}$ is obtained at $300 \mathrm{~mm} \mathrm{~min}^{-1}$. Fractures occur at the AA6056 side near the top and bottom surfaces and at the bonding interface in the middle section of the joints. The regions close to the top and bottom surfaces of the joints show a better ductility.
\end{abstract}

Keywords Bobbin tool friction stir welding $\cdot$ Dissimilar aluminum alloy $\cdot$ Bonding interface $\cdot$ Precipitation $\cdot$ Mechanical property

\section{Introduction}

Bobbin tool friction stir welding (BT-FSW) has been developed from friction stir welding (FSW), employing different tool structures and morphologies [1, 2]. In BT-FSW, the tool consists of a probe and two shoulders, namely the upper and lower shoulders. The upper shoulder serves the same

Available online at http://link.springer.com/journal/40195.

Wenya Li

liwy@nwpu.edu.cn

1 State Key Laboratory of Solidification Processing, Shaanxi Key Laboratory of Friction Welding Technologies, Northwestern Polytechnical University, Xi'an 710072, China

2 Institute of Materials Research, Materials Mechanics, Solid-State Joining Processes, Helmholtz-Zentrum Geesthacht, Max-Planck-Straße 1, 21502 Geesthacht, Germany

3 Institute of Product and Process Innovation, Leuphana University of Lüneburg, Universitätsallee 1, 21335 Lüneburg, Germany purpose as like in conventional FSW [3, 4], while the lower shoulder replaces the backing anvil typically used in FSW. With this arrangement, BT-FSW allows to weld closed or hollow structures. Moreover, the heterogeneous microstructure through the thickness of FSWed joint can be improved by BT-FSW. Xu et al. [5] examined the microstructure evolution in FSW and BT-FSW using electron backscattering diffraction (EBSD) to find homogeneously refined grains developing throughout the BT-FSWed joint thickness compared to the FSWed ones. In spite of this, the FSW joints typically have better mechanical properties than the BT-FSW joints [6], believing that the larger heat input due to the two shoulders is responsible to the decrease in the joint strength. However, the homogeneously refined grains are favorable to improve corrosion behavior of the joint. As investigated by Esmaily et al. [7], an improved corrosion resistance in BTFSWed joints was achieved as compared to FSWed joints. For lightweight manufacturing, Zhou et al. [8] carried out the BT-FSW of AZ61 magnesium alloy and reported the correlation between mechanical properties and rotational speeds. At the same time, they found a typical region, namely band pattern, where the voids form easily. Based on a coupled 
Eulerian-Lagrangian numerical model of the BT-FSW process developed in our previous study [9], the forming mechanism of the band pattern was illustrated. These investigations mentioned above have already provided some insights on the development of BT-FSW.

Joining of dissimilar aluminum alloys has gained significant attention of researchers in the past years due to combining the advantages of different aluminum alloys. However, there is a big challenge to obtain defect-free welds with good mechanical properties via fusion welding because of the melting and solidification process, especially for joining the 2XXX and 6XXX series aluminum alloys having significant differences in physical and chemical properties [10]. FSW is a solid-state welding process without melting issues, showing great potential in joining of dissimilar aluminum alloys $[11,12]$. The defect-free joints between AA6061 and AA2024 with excellent material mixing were produced via FSW, as reported by Ouyang et al. [13]. Meanwhile, they found that the microstructure exhibits distinct asymmetry characteristics at both sides of the joints. Moradi et al. [14] also confirmed that the different continuous dynamic recrystallization and overall texture intensity are present in this distinct asymmetric microstructure, attributing to the different nature of material mixing of dissimilar aluminum alloys. In order to improve material mixing, the effect of shoulder geometries on the FSW of dissimilar AA5083/AA6351 alloys was studied by Palanivel et al. [15], reporting excellent mechanical strength and material flow produced by a full impeller featured shoulder. At the same time, another factor affecting the material mixing, material configuration in FSW of dissimilar aluminum alloy was investigated as well. In this regard, Yan et al. [16] found that excellent material mixing and joint fatigue properties are produced when the $\mathrm{Al}-\mathrm{Zn}-\mathrm{Mg}$ alloy was placed on the advancing side (AS), and it became worse by the contrary material configuration. For a detailed review on FSW of dissimilar aluminum alloy joints [17], the development prospects for joining dissimilar aluminum joints are discussed. In summary, a significant amount of investigation has been done on the FSW of dissimilar aluminum alloys.

At present, BT-FSW of dissimilar aluminum alloys has not been studied extensively as compared to FSW. The AA2219 and AA2195 aluminum alloys have been joined by BT-FSW $[18,19]$, where the macroscopic features and microstructure of the joints were investigated. However, the investigated aluminum alloys are from the same alloy series, where the difference in chemical compositions and mechanical properties is limited. In the recent review by Fuse et al. [20], it is stated that BT-FSW of dissimilar materials needs further investigation. In this regard, in the present study, the BT-FSW of AA6056-T4 and AA2219-T87 dissimilar aluminum alloys was carried out to analyze the joint formation, bonding interface characteristics and mechanical properties.

\section{Experimental}

The AA6056-T4 and AA2219-T87 plates with dimensions of $250 \mathrm{~mm} \times 90 \mathrm{~mm} \times 4 \mathrm{~mm}$ were selected as the base material (BM) with chemical compositions as listed in Table 1 and placed on the RS and AS, respectively, as shown in Fig. 1. The tool is composed of two $15 \mathrm{~mm}$ diameter shoulders, i.e., the upper and lower shoulders, and a $7 \mathrm{~mm}$ diameter cylindrical probe. The BT-FSW without an offset was performed along the longitudinal direction of the plate on a five-axis kinematic robot system (PKM-T805). The gap size between the two shoulders was controlled by a constant gap force of $3300 \mathrm{~N}$. Different welding speeds varying from 300 to $400 \mathrm{~mm} \mathrm{~min}^{-1}$ were used at a constant rotational speed of $500 \mathrm{rpm}$. The metallographic samples were cut perpendicular to the welding direction and then etched using BARKER at $24 \mathrm{~V}$ for $200 \mathrm{~s}$ following polishing. Microstructure characteristics were checked by optical microscope (OM) and scanning electron microscope (SEM). Differential scanning calorimetry (DSC) samples were produced as $5 \mathrm{~mm}$ diameter wafer with $50 \mathrm{mg}$ weight and then tested on a DSC 200 F3 Maia machine. The temperature cycle was set at rate of $20{ }^{\circ} \mathrm{C} \mathrm{min}{ }^{-1}$ during the heating cycle from 20 to $590{ }^{\circ} \mathrm{C}$. The tensile samples were cut perpendicular to the welding direction and prepared according to ASTM-E8E. Tensile tests were performed on a Zwick and Roell machine using a constant crosshead speed of $1 \mathrm{~mm} \mathrm{~min}^{-1}$. Microhardness measurements were performed on Vickers hardness tester (LECO, M-400-H) at a load of $200 \mathrm{~g}$ for $10 \mathrm{~s}$. The SEM was also used to study the fracture surface of the joints.

\section{Results and Discussion}

\subsection{Force and Heat Input Energy Variations}

Figure 2a shows the force variations in the welding direction and the torque during BT-FSW process for different welding
Table 1 Chemical compositions of the AA6056 and AA2219 plates $(\mathrm{wt} \%)$

\begin{tabular}{lllllll}
\hline AA6056-T4 & $\mathrm{Al}$ & $\mathrm{Mg}$ & $\mathrm{Si}$ & $\mathrm{Cu}$ & $\mathrm{Mn}$ & $\mathrm{Fe}$ \\
& $\mathrm{Bal}$. & 0.73 & 0.87 & 0.67 & 0.62 & 0.12 \\
AA2219-T87 & $\mathrm{Al}$ & $\mathrm{Cu}$ & $\mathrm{Mn}$ & $\mathrm{Ti}$ & $\mathrm{Zr}$ & $\mathrm{Si}$ \\
& $\mathrm{Bal}$. & 6.38 & 0.32 & 0.06 & 0.18 & 0.08 \\
\hline
\end{tabular}



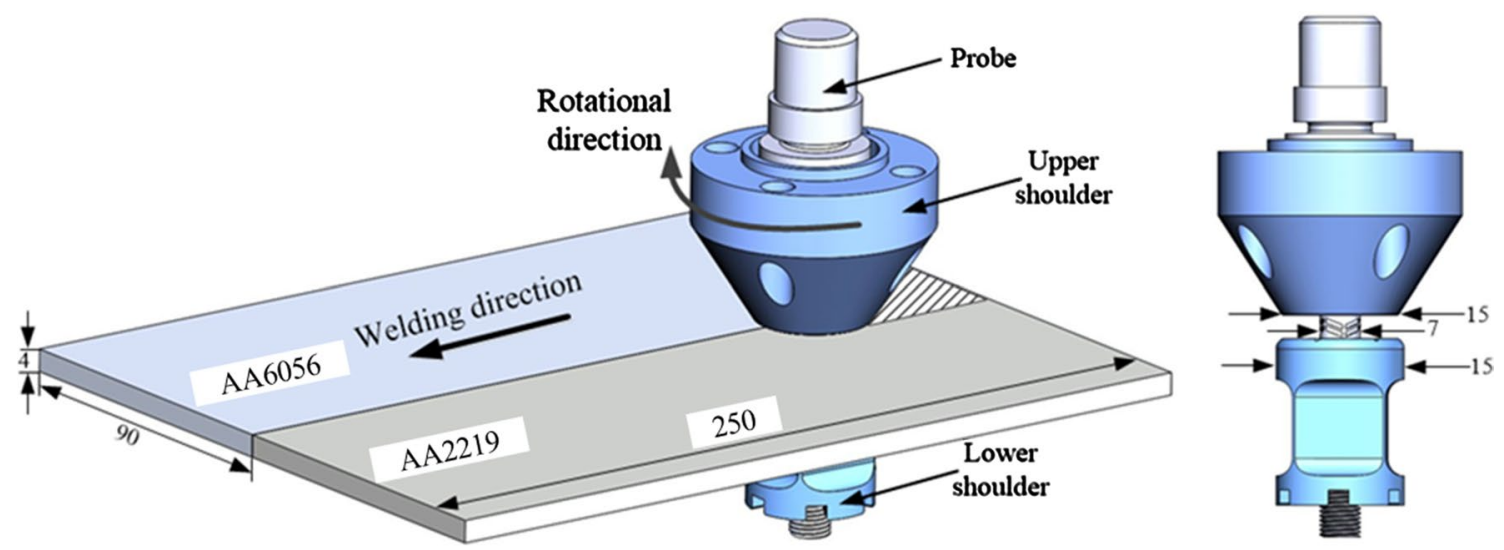

Fig. 1 BT-FSW process of dissimilar aluminum alloys

parameters. Both the force and torque increase rapidly at the beginning of the process, where after the run-in time the values slightly decrease with continuous process time. As measured by Goebel et al. [21], the total torque of $50 \mathrm{~N} \mathrm{~m}$ developing in BT-FSW is considerably higher than that in FSW, which increases the risk of pin breakage. Huang et al. $[22,23]$ proposed a novel self-support tool to prevent pin breakage in BT-FSW process. Meanwhile, this tool can easily adapt the change in thickness of the plate to simplify the welding process [24], providing a new outlook for the development of BT-FSW. Later into the process, materials get soften from frictional heat, which results into slight reduction of force and torque. As the welding speed varies from 300 to $400 \mathrm{~mm} \mathrm{~min}^{-1}$, the force and torque increase from 1300 to $2200 \mathrm{~N}$ and from 42 to $45 \mathrm{~N} \mathrm{~m}$, respectively. Therefore, the force in the welding direction is more sensitive to

(a)

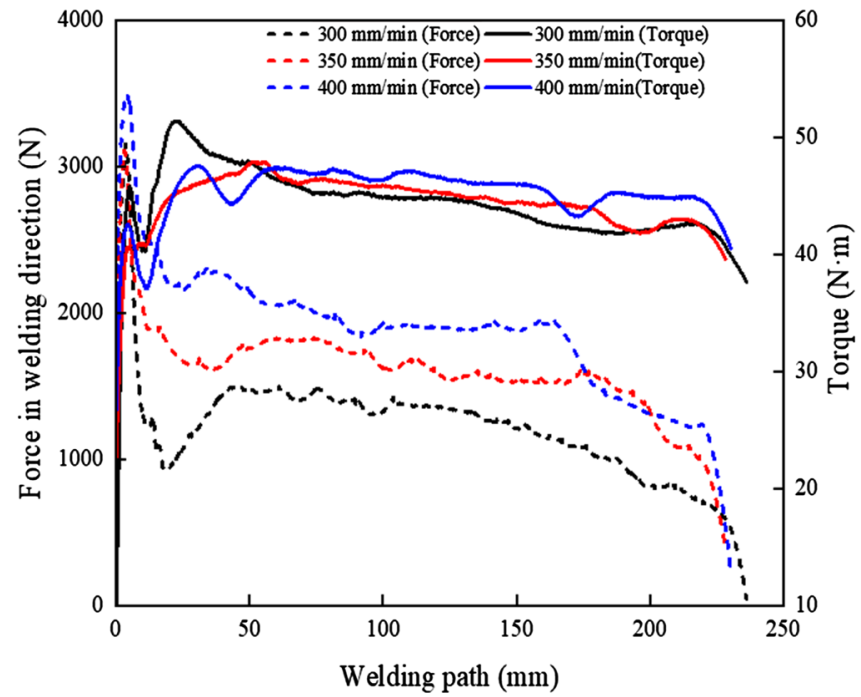

the variation of welding speeds as compared to the torque. Figure $2 b$ shows the line energy (i.e., welding heat input per unit length) change during welding, where the line energy is inversely proportional to the welding speed. During welding, the line energy decreases with increasing welding speed. It is expected that frictional heat is transferred through conduction, which further softens the material when the tool moves to the end position of the weld [25], thereby further reducing the resulting line energy.

\subsection{Bonding Interface Characteristics}

Cross-sectional micrographs of the joints at various welding speeds are presented in Fig. 3, where it can be seen that the bonding interface at joint shows a linear shape for all welding parameters. Yan et al. [26] stated that an irregular

(b)

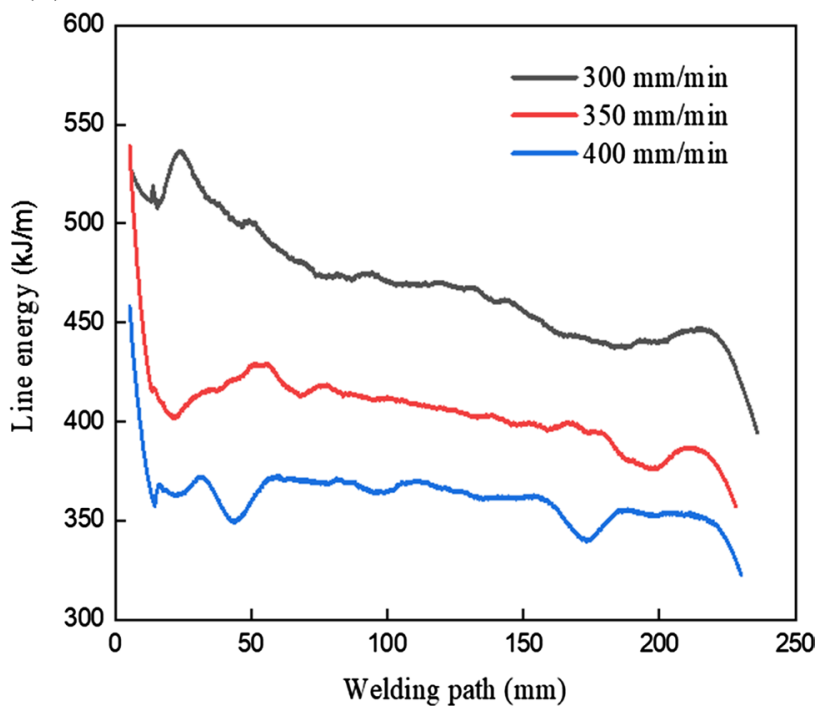

Fig. 2 Variations of $\mathbf{a}$ the force in the welding direction and torque, $\mathbf{b}$ line energy for different welding parameters 
or wiggly bonding interface in case of dissimilar aluminum alloy joints indicates excellent material flow and mixing. In other words, a linear bonding interface in the present study is associated with a weak material flow, which may be related to the placement of the plates rather than with the welding parameters itself. This assumption stems from the fact that the bonding interface shape remains unaffected for the different welding parameters. A sound joint is produced at $300 \mathrm{~mm} \mathrm{~min}^{-1}$, as shown in Fig. 3a. As the welding speed further increases, voids are formed in the joint. There is a proportional relationship between welding speed and the size of void, due to reduced material plasticity at higher welding speeds. It should be noted that all voids are observed in the stir zone (SZ) of the AA2219 side, close to the thermo-mechanically affected zone (TMAZ). The reason is that AA6056 has lower hardness and yield strength and shows better ductility than that of AA2219, thus, processing a better plastic formability than AA2219. During the welding process, AA6056 adhered to the rotating tool moves from the RS to the AS, and then, it is released from the rotating tool. However, it is difficult to embed AA6056 into AA2219 due to their difference in mechanical properties. Thus, the distinct bonding interface is formed. Besides, the restricted material does not fill the empty region caused by the forward movement of the probe, leaving the voids at the SZ near the AA2219 side.

The microstructures of the typical regions marked in Fig. 3a are shown in Fig. 4. Zones A and B belong to the top and middle sections of the TMAZ of the joint on the AS, respectively. As shown in Fig. 4a, the material is deformed plastically by the rotating shoulder, producing severely deformed elongated grain. There is a linear bonding interface between the TMAZ and the SZ in the micrograph taken at the middle section (Fig. 4b), correlating to the limited shear action of the probe. In this region, the grains are less deformed compared to the top section. Figure $4 \mathrm{c}, \mathrm{d}$ displays the bonding interface features at

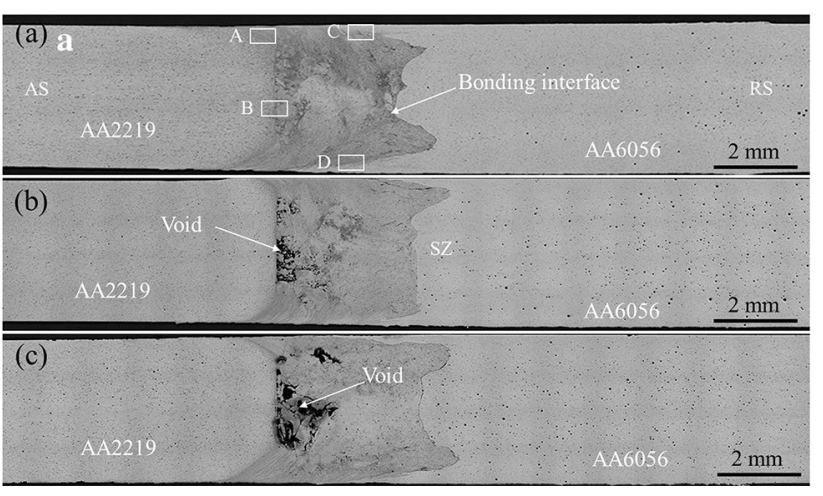

Fig. 3 Macrographs of the BT-FSWed joints with different welding speeds: a $300 \mathrm{~mm} \mathrm{~min}^{-1}$, b $350 \mathrm{~mm} \mathrm{~min}^{-1}$, c $400 \mathrm{~mm} \mathrm{~min}^{-1}$ the top and bottom sections within the SZ, respectively. The AA2219 and AA6056 are intermixed together near the upper and lower shoulders, and the bonding interface shows an irregular and jagged pattern due to excellent material mixing. Material flow in BT-FSW process shows a dumbbell-shaped distribution, with higher shear and stirring velocities formed close to both shoulders instead of the probe [9]. Thus, appropriate material flow is predisposed to form near the two shoulders, which facilitates the intermixing of the bonding interfaces.

Figure 5 shows the bottom and middle sections of bonding interface within the SZ for different welding speeds. With increasing welding speed, the material intermixing at the bottom bonding interface becomes weaker, and a distinct bonding interface boundary is obtained at $400 \mathrm{~mm} \mathrm{~min}^{-1}$. It is correlated to a decrease in stirring intensity per unit length with increased welding speed for a constant rotational speed. In contrast, the middle section of the bonding interface morphology rarely changes as welding speed increases. An irregular wavy bonding interface is developed at the welding speed of $300 \mathrm{~mm} \mathrm{~min}^{-1}$. The distinct bonding interfaces are formed simultaneously at welding speeds of $350 \mathrm{~mm} \mathrm{~min}^{-1}$ and $400 \mathrm{~mm} \mathrm{~min}^{-1}$. In summary, the welding speed has a significant effect on the behavior of the bonding interface near both shoulders. Material flow at the top and bottom sections of bonding interface is stronger than in the middle section, especially for the low welding speed used.

Figure 6a exhibits the SEM images of the middle section of bonding interface in the SZ, showing a complete mixing of the two metals without any defects. Secondary phase particles are found near the bonding interface, with the particle numbers and size on the AA2219 side found larger than on the AA6056 side. Besides, particles with large size still remain though intense stirring in the SZ. From the EDS analysis presented in Fig. $6 \mathrm{~b}, \mathrm{Mg}, \mathrm{Cu}$ and $\mathrm{Fe}$ elements at the bonding interface fluctuate, which affects the mechanical properties of the joints.

Figure 7a shows the DSC curves of the heat affected zone (HAZ) on the AA2219 side for different welding speeds. Two obvious exothermic peaks are observed for all welding speeds, which is the $\theta^{\prime}$ phase precipitation at $250-300{ }^{\circ} \mathrm{C}$ and the $\theta$ phase precipitation at $480-520^{\circ} \mathrm{C}$, respectively. Furthermore, an endothermic peak at $200-250{ }^{\circ} \mathrm{C}$ is correlated with the dissolution of the $\theta^{\prime \prime}$ phase. According to Papazian [27], the precipitate sequence for AA2219 aluminum alloy is summarized as $\alpha$ (SSSS) $\rightarrow$ Guinier-Preston (GP) zones $\rightarrow \theta^{\prime \prime} \rightarrow \theta^{\prime} \rightarrow \theta$, and normally, the dissolution of GP zones at $50-200{ }^{\circ} \mathrm{C}$ takes precedence over the $\theta^{\prime \prime}$ dissolution. However, there are no GP zones dissolution detected in this study, which is in accordance with results reported by Cui et al. [28]. This may be correlated to the different welding techniques and thermal histories employed. In 

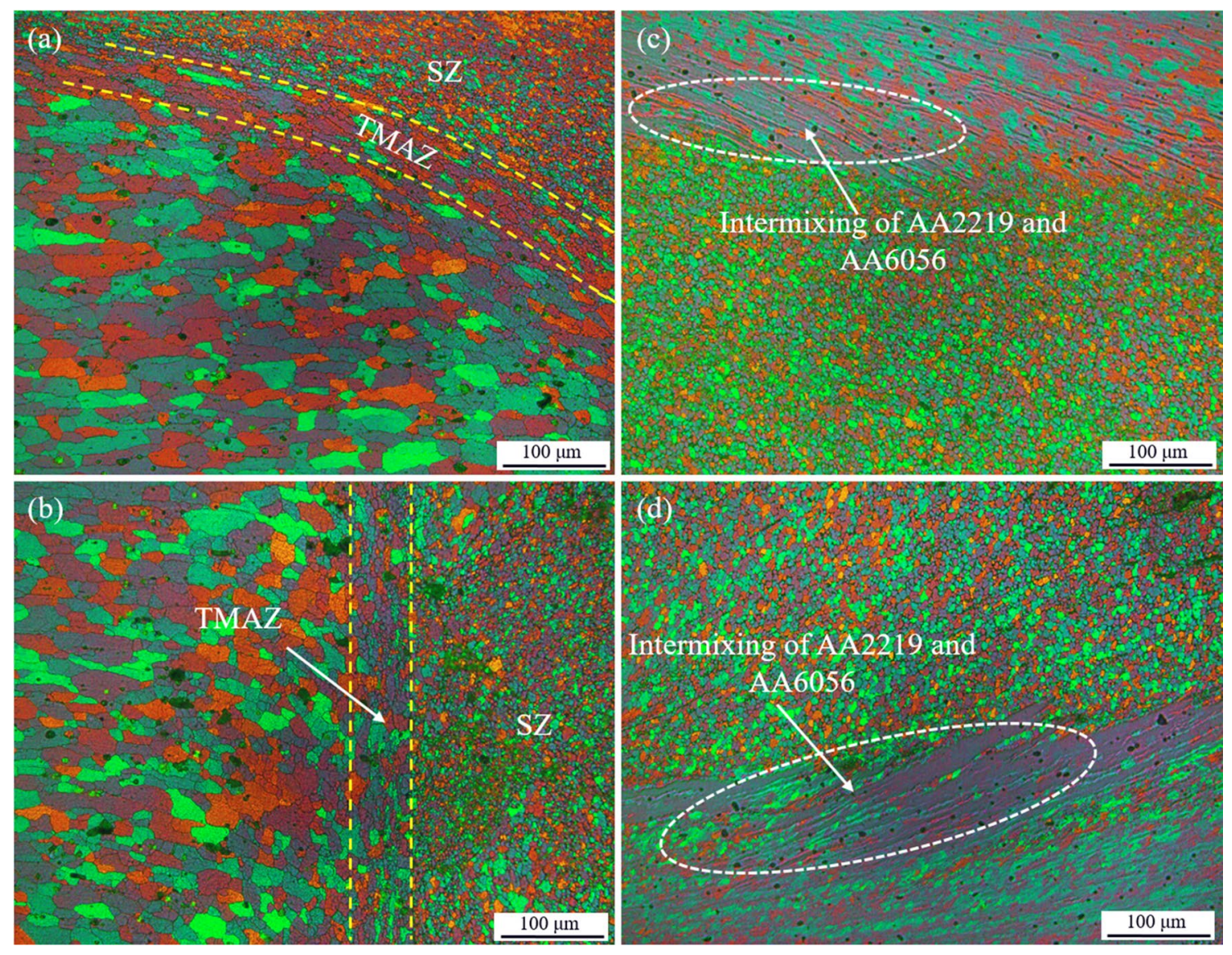

Fig. 4 Microstructures of the different zones marked in Fig. 3a: a zone A, b zone B, c zone C, $\mathbf{d}$ zone D

case of the $\theta^{\prime \prime}$ dissolution, the corresponding endothermic peak area is not affected by the welding speed in the range $300-350 \mathrm{~mm} \mathrm{~min}^{-1}$, but an increase in endothermic peak is found at the welding speed of $400 \mathrm{~mm} \mathrm{~min}{ }^{-1}$. This indicates that the HAZ has undergone lower temperature than those reached at $300 \mathrm{~mm} \mathrm{~min}^{-1}$ and $350 \mathrm{~mm} \mathrm{~min}^{-1}$, thus avoiding the dissolution of $\theta^{\prime \prime}$ initially present in the BM during BT-FSW process. This is beneficial to the improvement of hardness at the AA2219 side, as depicted in Fig. 8. The AA6056-T4 aluminum alloy incorporates a massiveness of GP zones that dissolves during the heating stage, resulting in a large endothermic peak at $200{ }^{\circ} \mathrm{C}$ for the $\mathrm{BM}$, as shown in Fig. 7b. An exothermic peak B is found around $250{ }^{\circ} \mathrm{C}$, which is the precipitation of $Q$ phase. Compared with the BM, there is a decrease in the dissolution of GP zones at the HAZ on the AA6056 side, owning to partial dissolution of GP zones during the BT-FSW process. As welding speed increases, minor changes in the GP dissolution and the $Q$ phase precipitation are determined, reflecting the minor change in the precipitation phase of the HAZ at the AA6056 side.

\subsection{Mechanical Properties}

The inhomogeneous hardness distributions of the joints for different welding speeds are shown in Fig. 8, with hardness of the AA2219 side being higher than the AA6056 side. The hardness contour shows the typical "W" shape, with low hardness values located at the HAZ of both materials, in which it is quite similar to typical FSWed joint [29]. However, as observed by Xu et al. [5], the BT-FSWed joints have a symmetrical hardness distribution through the thickness direction in contrast to FSWed joints. This is the result of the process characteristics, where the lower and upper shoulders rotate at the same speed, producing symmetrical frictional heat and material flow in middle of the joints, and resulting in a homogeneous microstructure [30], properties [31] and even the distribution of residual stresses. Therefore, the symmetrical hardness distributions are found in this study as well. Figure 9 shows the curves of bonding interface of joints at different welding speeds. In the SZ, the hardness values on the AS are higher than those on the RS, due to the different properties between AA2219 and AA6056. There 

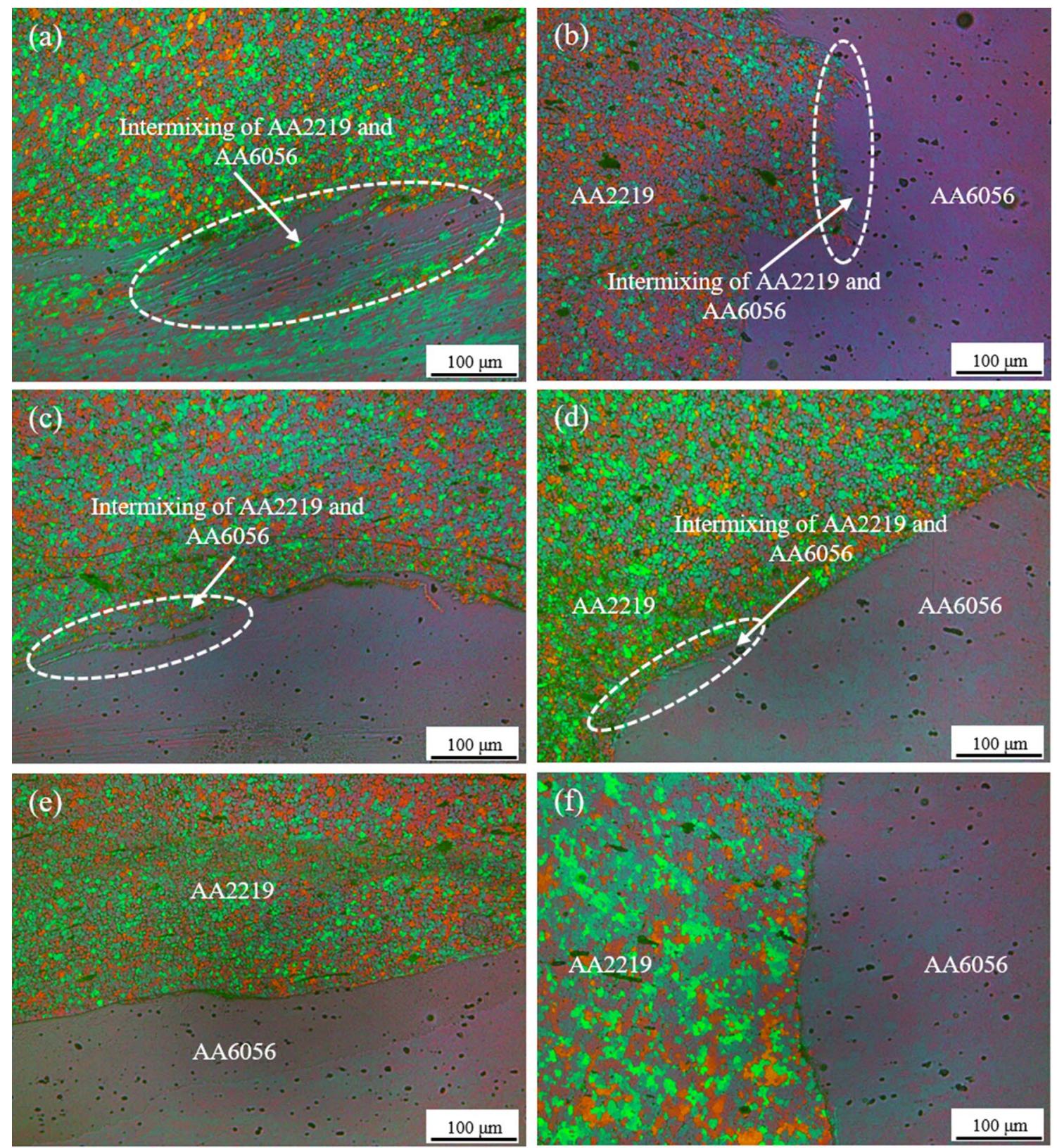

Bottom bonding interface

Middle bonding interface

Fig. 5 Bottom and middle sections of bonding interface of the joints welded at different welding speeds of a, b $300 \mathrm{~mm} \mathrm{~min}^{-1}$, c, d $350 \mathrm{~mm} \mathrm{~min}^{-1}$, e, f $400 \mathrm{~mm} \mathrm{~min}^{-1}$

is a sharp change in hardness in the SZ, where the hardness decreases from $135 \mathrm{HV}$ to $95 \mathrm{HV}$ near the bonding interface. Meanwhile, the hardness of the SZ rarely changes with increased welding speed. In case of welding speed of $400 \mathrm{~mm} \mathrm{~min}^{-1}$, an abrupt hardness drop in the SZ at the AA2219 side can be observed. The decreased hardness is attributed to the presence of void. The hardness in the HAZ at the AA2219 side remains unaffected for welding speeds of $300 \mathrm{~mm} \mathrm{~min}^{-1}$ and $350 \mathrm{~mm} \mathrm{~min}^{-1}$, but increases sharply at $400 \mathrm{~mm} \mathrm{~min}^{-1}$ due to the remaining $\theta^{\prime \prime}$ phase (Fig. 7a). At the AA6056 side, the HAZ hardness is not largely dependent on welding speed and shows a weaker relationship in comparison with the HAZ of the AA2219 side. The different precipitation phases across the joint (presented in Fig. 7b) are the reasons for the differences in the hardness distributions of both HAZs.

Figure 10 presents the tensile strength and elongation of the joints as a function of welding speeds. 

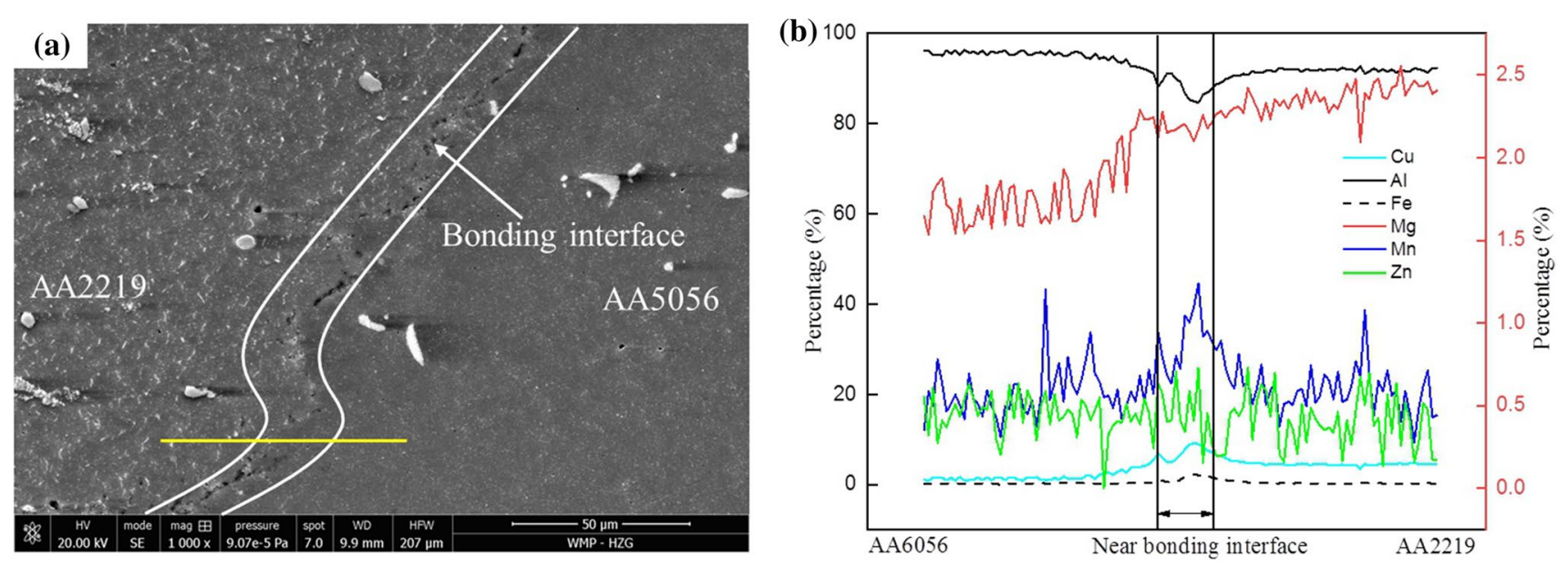

Fig. 6 a Bonding interface of the joint obtained at $300 \mathrm{~mm} \mathrm{~min}^{-1}$; $\mathbf{b}$ EDS analysis of the bonding interface

(a)

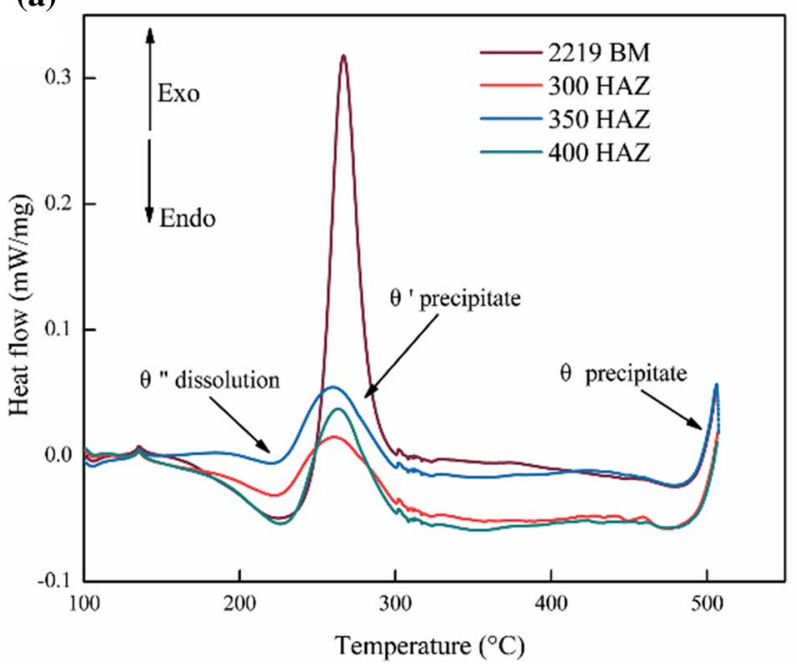

(b)

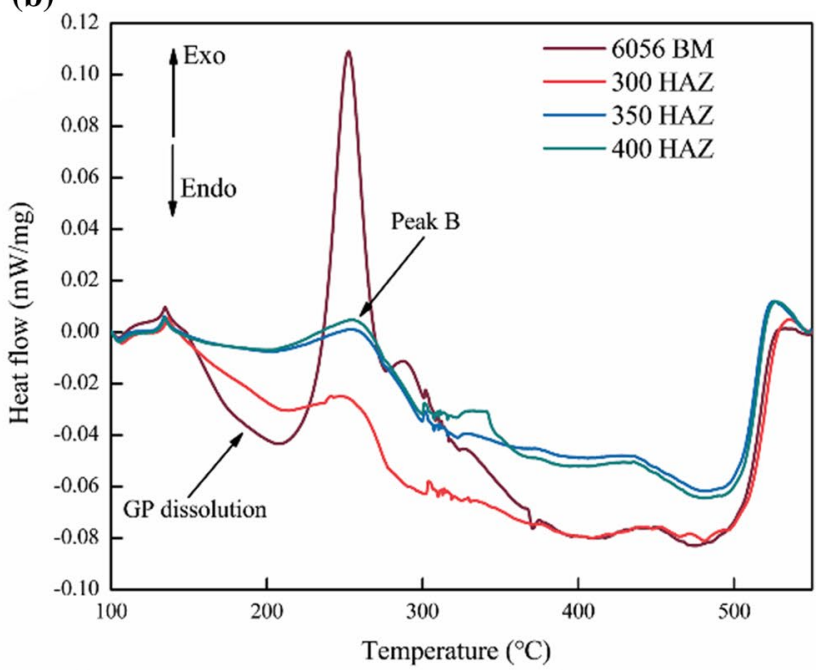

Fig. 7 DSC curves of the BM and HAZ a at the AA2219 side, b AA6056 side for different welding speeds

As seen, the tensile strength and elongation decrease with increasing welding speeds. The maximum tensile strength of $181 \mathrm{MPa}$ is obtained at the welding speed of $300 \mathrm{~mm} \mathrm{~min}^{-1}$, which is $40.2 \%$ of the AA2219 BM (450 MPa) and $52.6 \%$ of AA6056 (330 MPa). A relevant study on the FSW of dissimilar AA6056/AA2024 alloys was reported by Amancio-Filho et al. [32], who concluded excellent material mixing with lamellar pattern between AA2024 and AA6056 alloys, and the maximum tensile strength of $246 \mathrm{MPa}$ is $55.8 \%$ of AA2024 (440 MPa) and $71.4 \%$ of AA6056 (344 MPa), respectively. Therefore, lower strength of the dissimilar alloys joint is achieved by BT-FSW compared with FSWed joint. Similar results were reported by Goetze et al. [33], who believed that the declined strength is mainly correlated to the simpler material mixing patterns of the dissimilar alloys in BT-FSW. In the present study, the bonding interface produced with $300 \mathrm{~mm} \mathrm{~min}{ }^{-1}$ owns better material mixing than those produced with other welding speeds (Fig. 5), which yields to the best joint strength in this study.

Figure 11 presents the cross sections of the fracture joints at different welding speeds. As seen, fractures in all joints occur at the AA6056 side near the top and bottom surface and at the bonding interface in the mid-thickness of the joints, indicating a weaker bonding interface. As mentioned above, excellent material mixing is formed 


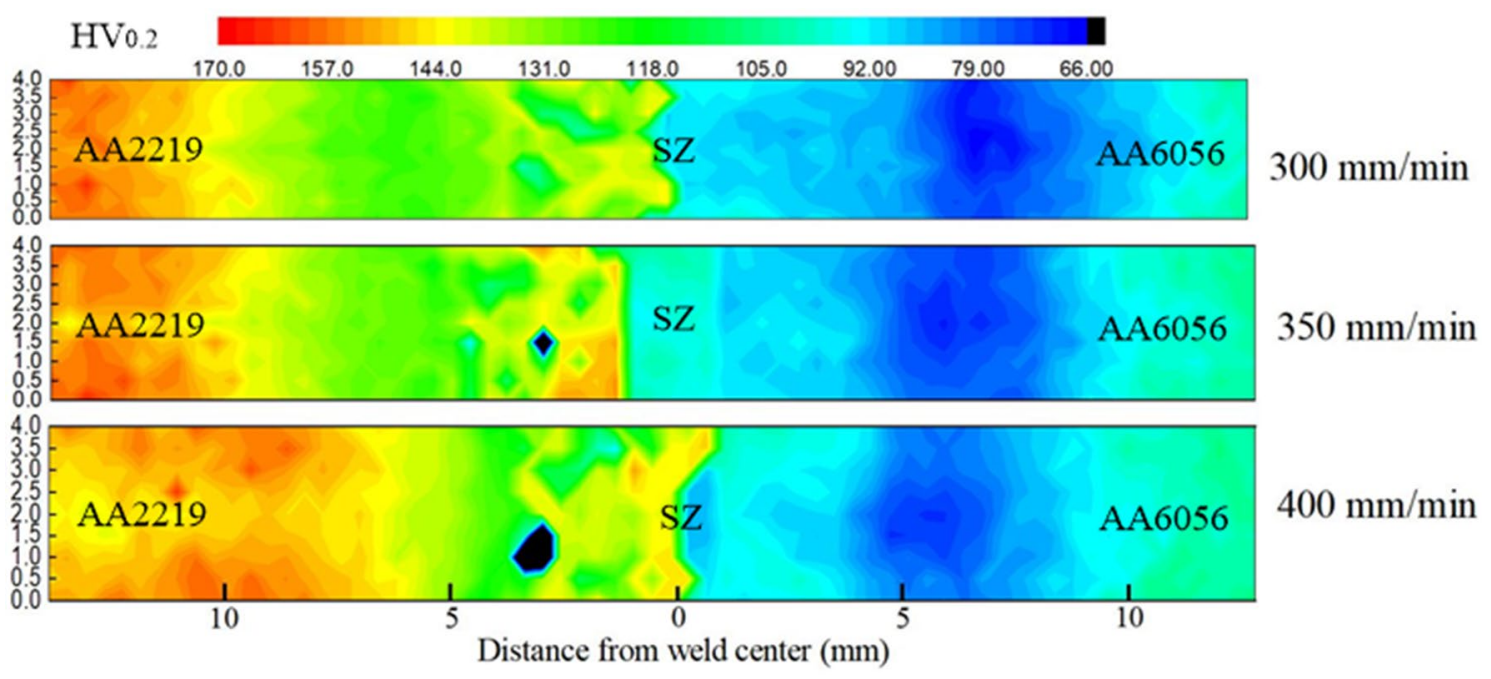

Fig. 8 Hardness maps across the cross section of the joints at different welding speeds

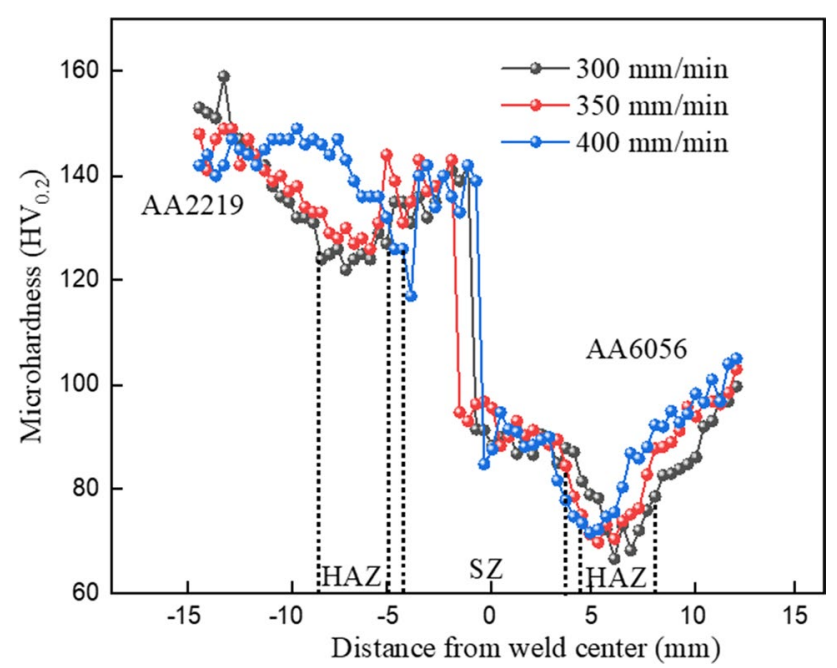

Fig. 9 Hardness curves of bonding interface at the weld center for different welding speeds

near both surfaces due to the rotating shoulders, which improves the interfacial bonding strength of AA6056 and AA2219 in this region. In contrast, the limited material mixing is formed at the middle position and becomes the preferred region for crack propagation during tensile testing. Figure 12 shows the SEM morphologies of typical positions marked in Fig. 11. As it can be seen from the images, a large number of dimples with small size as well as tearing ridges exist on the fracture surfaces near the top surface (Fig. 12a, c), and the lamellar microstructures without any dimples are formed on the middle position of

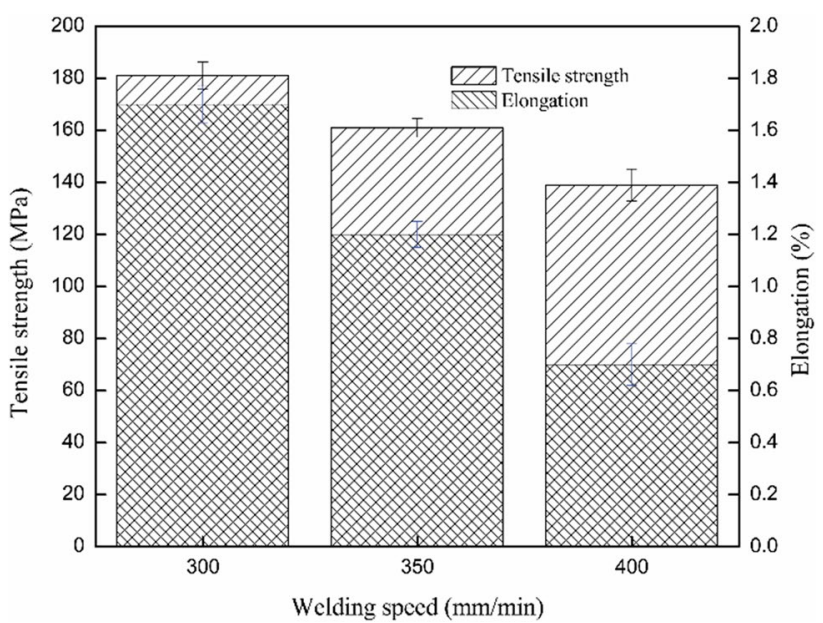

Fig. 10 Tensile strength and elongation at different welding speeds

the joint (Fig. 12b, d). In general, dimple structures are associated with good ductility; thus, the regions close to the top and bottom surfaces own better ductility than the mid-thickness of the joints.

\section{Conclusions}

In the present study, the dissimilar AA2219 and AA6056 alloys were successfully joined via bobbin tool friction stir welding. The force history during welding, the microstructure evolution and mechanical properties of the joints were investigated in detail. The conclusions are summarized as follows: 


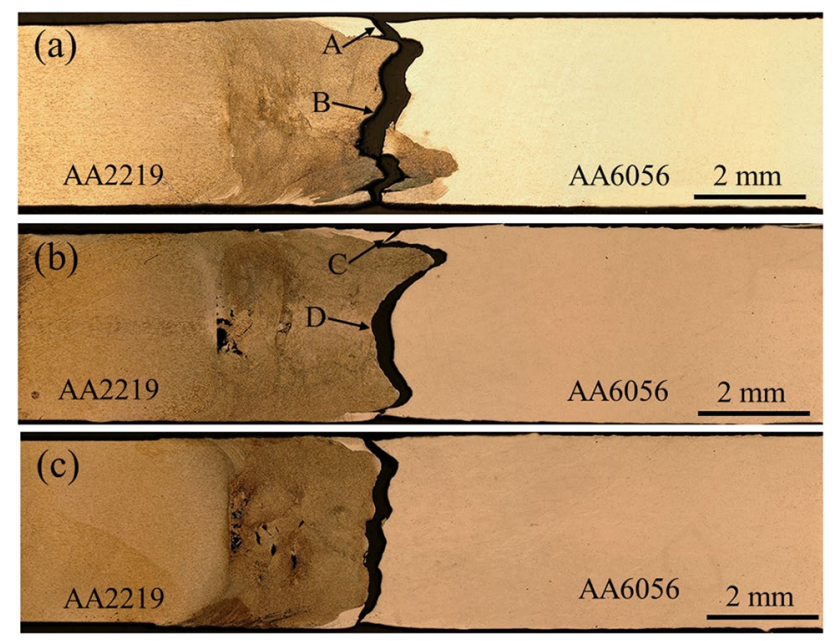

Fig. 11 Cross sections of the fracture joints welded at different welding speeds: a $300 \mathrm{~mm} \mathrm{~min}^{-1}$, b $350 \mathrm{~mm} \mathrm{~min}^{-1}$ and c $400 \mathrm{~mm} \mathrm{~min}^{-1}$

1 An increase in welding speed leads to an increase in the force in welding direction from $1300 \mathrm{~N}$ to $2200 \mathrm{~N}$ and a decrease in the line energy from 473 to $368 \mathrm{~kJ} \mathrm{~m}^{-1}$. Both the force and torque reach their maximum value at the beginning of the welding.
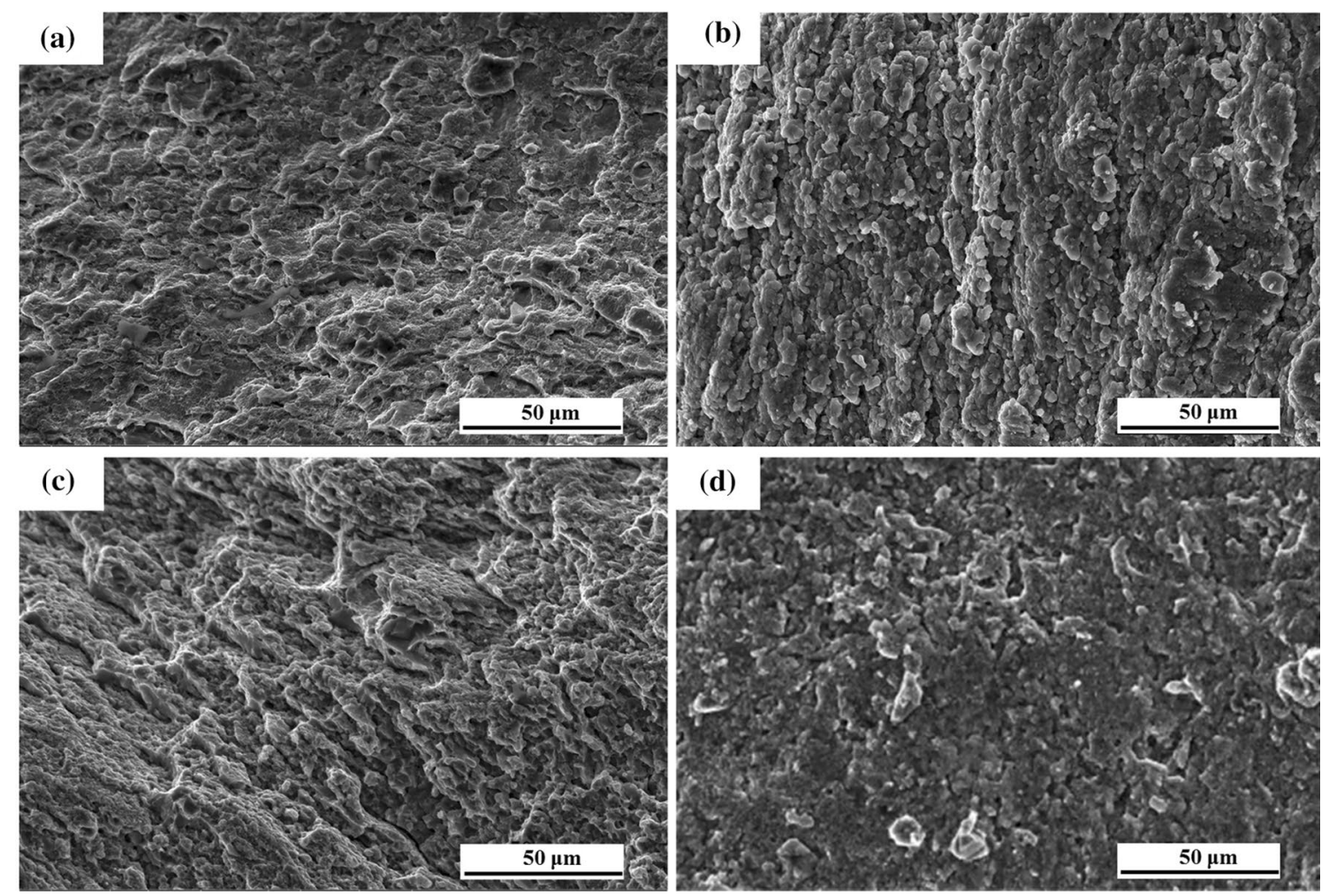

Fig. 12 SEM morphologies of typical positions in Fig. 11: a zone A, b zone B, c zone C and d zone D 
Acknowledgements Quan Wen is grateful for the support provided by the China Scholarship Council (No. 201806290070), and Wenya Li thanks the fund by the State Key Laboratory of Solidification Processing in NWPU (No. 2019-QZ-01).

\section{References}

[1] G.Q. Wang, Y.H. Zhao, Y.Y. Tang, Acta Metall. Sin. (Engl. Lett.) 33, 13 (2020)

[2] F.F. Wang, W.Y. Li, J. Shen, Q. Wen, J.F. dos Santos, J. Mater. Sci. Technol. 34, 135 (2018)

[3] L. Ma, S.Y. Niu, S.D. Ji, P. Gong, Arch. Metall. Mater. 65, 307 (2020)

[4] M. Guan, Y.H. Wang, Y.X. Huang, X. Liu, X.C. Meng, Y.M. Xie, J.C. Li, Mater. Lett. 255, 126506 (2019)

[5] W.F. Xu, Y.X. Luo, M.W. Fu, Mater. Charact. 138, 48 (2018)

[6] A.L. Lafly, D. Alléhaux, F. Marie, C. Dalle Donne, G. Biallas, Weld. World 50, 98 (2006)

[7] M. Esmailya, N. Mortazavi, W. Osikowicz, H. Hindsefelt, J.E. Svensson, M. Halvarsson, G.E. Thompson, L.G. Johansson, Corros. Sci. 111, 98 (2016)

[8] L. Zhou, G.H. Li, G.D. Zha, F.Y. Shu, H.J. Liu, J.C. Feng, Sci. Technol. Weld. Join. 23, 596 (2018)

[9] Q. Wen, W.Y. Li, Y.J. Gao, J. Yang, F.F. Wang, Int. J. Adv. Manuf. Technol. 100, 2679 (2019)

[10] X.Q. Liu, H.J. Liu, Yan Yu. Acta Metall. Sin. (Engl. Lett.) 33, 115 (2020)

[11] X. Feng, S.B. Li, L.N. Tang, H.M. Wang, Acta Metall. Sin. (Engl. Lett.) 33, 30 (2020)

[12] B. He, L. Cui, D.P. Wang, H.J. Li, C.X. Li, Acta Metall. Sin. (Engl. Lett.) 33, 135 (2020)

[13] J.H. Ouyang, R. Kovacevic, J. Mater. Eng. Perform. 11, 51 (2002)

[14] M.M. Moradi, H.J. Aval, R. Jamaati, S. Amirkhanlou, S.X. Ji, J. Manuf. Process. 32, 1 (2018)
[15] R. Palanivel, R. Laubscher, S. Vigneshwaran, I. Dinaharan, Proc. Inst. Mech. Eng. Part B: J. Eng. Manuf. 232, 1384 (2016)

[16] Z.J. Yan, X.S. Liu, H.Y. Fang, Acta Metall. Sin. (Engl. Lett.) 29, $1161(2016)$

[17] V. Patel, W.Y. Li, G.Q. Wang, F.F. Wang, A. Vairis, P.L. Niu, Metals 9, 270 (2019)

[18] M. Skinner, R.L. Edwards, Mater. Sci. Forum 426-432, 2849 (2003)

[19] D.E. Taylor, Dissertation, Louisiana State University (2009)

[20] K. Fuse, V. Badheka, Sci. Technol. Weld. Join. 24, 277 (2019)

[21] J. Goebel, M. Reimann, J.F. dos Santos, J. Mater. Eng. Perform. 27, $5212(2018)$

[22] Y.X. Huang, L. Wan, S.X. Lv, J.C. Feng, Sci. Technol. Weld. Join. 18, 239 (2013)

[23] Y.X. Huang, L. Wan, T.F. Huang, Z.L. Lv, L. Zhou, J.C. Feng, Int. J. Adv. Manuf. Technol. 87, 1067 (2016)

[24] L. Wan, Y.X. Huang, W.Q. Guo, S.X. Lv, J.C. Feng, J. Mater. Sci. Technol. 30, 1243 (2014)

[25] S.D. Ji, Y.Y. Jin, Y.M. Yue, S.S. Gao, Y.X. Huang, L. Wang, J. Mater. Sci. Technol. 29, 955 (2013)

[26] Z. Yan, X. Liu, H. Fang, J. Mater. Sci. Technol. 32, 1378 (2016)

[27] J.M. Papazian, Metall. Trans. A 12, 269 (1981)

[28] L. Cui, P. Lu, W.K. Li, H.M. Wang, D.P. Wang, Z.P. Zhang, J.L. Song, Sci. Technol. Weld. Join. 24, 27 (2019)

[29] H.J. Zhang, M. Wang, X. Zhang, G. Yang, Mater. Des. 65, 559 (2015)

[30] J.J. Shen, F.F. Wang, U.F.H. Suhuddin, S.Y. Hu, W.Y. Li, J.F. dos Santos, Metall. Mater. Trans. A 46, 2809 (2015)

[31] J.H. Dong, C. Gao, Y. Lu, J. Han, X.D. Jiao, Z.X. Zhu, Int. J. Miner Metall. Mater. 24, 171 (2017)

[32] S.T. Amancio-Filho, S. Sheikhi, J.F. dos Santos, C. Bolfarini, J. Mater. Process. Technol. 206, 132 (2008)

[33] P. Goetze, M. Kopyściański, C. Hamilton, S. Dymek, in Friction Stir Welding and Processing X, ed. by Y. Hovanski, R. Mishra, Y. Sato, P. Upadhyay, D. Yan (Springer, Basel, 2019), p. 3 